\title{
Serogroup C invasive meningococcal disease among men who have sex with men and in gay-oriented social venues in the Paris region: July 2013 to December 2014
}

\author{
L Aubert (lyderic.aubert@ars.sante.fr) ${ }^{1}$, M K Taha ${ }^{2}$, N Boo ${ }^{3}$, Y Le Strat ${ }^{4}$, A E Deghmane ${ }^{2}$, A Sanna ${ }^{1}$, A S Barret ${ }^{4}$, D Lévy-Bruhl ${ }^{4}$, \\ S Vandentorren ${ }^{1}$, I Parent du Châtelet ${ }^{4}$ \\ 1. French Institute for Public Health Surveillance (InVS) in Paris region, Paris, France \\ 2. National Reference Centre for Meningococci (NRC), Institute of Pasteur, Paris, France \\ 3. Regional Public Health Agency (ARS) in the Paris region, Paris, France \\ 4. French Institute for Public Health Surveillance (InVS), Saint-Maurice, France
}

In November 2014, French public health authorities renewed the recommendation to target for vaccination against invasive meningococcal disease men who have sex with men (MSM) and all individuals $\geq 25$ years attending social venues associated with the gay community. This policy was extended beyond the Paris region as a reaction to the continuing spread of serogroup $C$ isolates belonging to a new lineage within clonal complex cc11 since the recommendation was first issued in July 2013.

In this report, we describe, based on combined epidemiological surveillance data and genetic typing of serogroup $C$ meningococcal isolates, the spread of a specific invasive strain of meningococcus C (MenC) in the Paris region that had started as an outbreak among men who have sex with men (MSM) in June 2013.

\section{The alert in June 2013}

In the first half of 2013,14 serogroup C IMD cases were reported in France in 25 to 59 year-old men, while six cases were reported in women. Of the adult male cases, six affected residents of the Paris region and three occurred within one week in early June in MSM. The variable regions 1 and 2 of PorA, the variable region of FetA and the clonal complex (cc) of the three isolates were characterised. These isolates showed the genotype $C: P 1.5-1,10-8: F: 3-6: C C 11$ and belonged to the electrophoretic type (ET) 15 of the cc11 (cc11 harbours several lineages). Between October 2012 and May 2013, five serogroup C IMD cases in MSM were also reported in Germany [1], caused by isolates sharing the same characteristics as the ones in France. Further genetic analysis showed that the German and the French isolates shared additional markers that also differed from other lineages of the cc11 isolates (data not shown). These findings raised the question of the emergence of a new clone of serogroup C Neisseria meningitidis in the European MSM community [2]. Considering that serogroup $\mathrm{C}$ outbreaks occurred also among MSM in Canada in 2001 and in the United States in 2003 (Chicago) and in 2011-13 (New York City), a rapid risk assessment was prepared by the European Centre for Disease Prevention and Control (ECDC) in July $2013[3,4]$.

We established a national enhanced surveillance and prompted the regional public health officers to assess a possible link to the MSM community for all cases infected by $C: P 1.5-1,10-8: F: 3-6: C C 11$ isolates.

\section{Serogroup C invasive meningococcal disease cases in the Paris region from July 2013 to December 2014}

Since July 2013, 34 cases of serogroup C IMD have been notified in the Paris region and two other cases have been diagnosed in other countries but were very likely to be linked to a source of exposure in the Paris region. Among these 36 cases, 17 were 25 to 59 yearsold and five were aged 60 years and older. The case fatality rate was $17 \%(6 / 36)$. The male/female ratio was $1.6(22 / 14)$ (Table1). None of the cases had been vaccinated against MenC disease.

Isolates from 29 of the 36 cases were subjected to a complete molecular analysis and 14 were related to the genotype C:P1.5-1,10-8:F3-6:Cc11. Among those 14, nine isolates showed the above-mentioned additional specific markers (Figure1). They corresponded to seven men (one aged 15-24 years and six aged 25-59 years) and two women (one aged 25-59 years and one in the age group 60 years and older). One additional male case (15-24 years-old) was epidemiologically linked to one of them (family cluster). These 10 cases were directly or indirectly linked to the MSM community (four cases aged 25-59 years who self-identified as MSM and six who did not identify as MSM but attended social venues associated with the gay community in the Paris region). 


\section{Incidence rates and risk evaluation}

When considering all reported serogroup C IMD cases for all age-groups and both women and men, no excess of cases was observed in the Paris region compared with the general population of France since July 2013. In contrast, we observed a gradual increase in the incidence of serogroup C IMD in the Paris region since 2013, a trend that was less marked elsewhere in France (Figure 2).

Moreover, IMD caused by C:P1.5-1,10-8:F3-6:CC11 isolates have increased since 2011 particularly in the Paris region where it represented about half $(11 / 22)$ of the notified meningococcus C IMD cases in 2014 (vS 12\% elsewhere in France, $p<10^{-3}$ ). During the period from 2011 to 2014 , the mean annual reporting rate for these isolates was estimated at 0.05 cases per 100,000 inhabitants in the Paris region (vs 0.02 elsewhere in France, $\left.\mathrm{p}<10^{-3}\right)$.

\section{FIGURE 1}

Cases of serogroup C invasive meningococcal disease by month of hospitalisation and genotypic combination, Paris region, France, 1 July 2013-31 December $2014(n=36)$

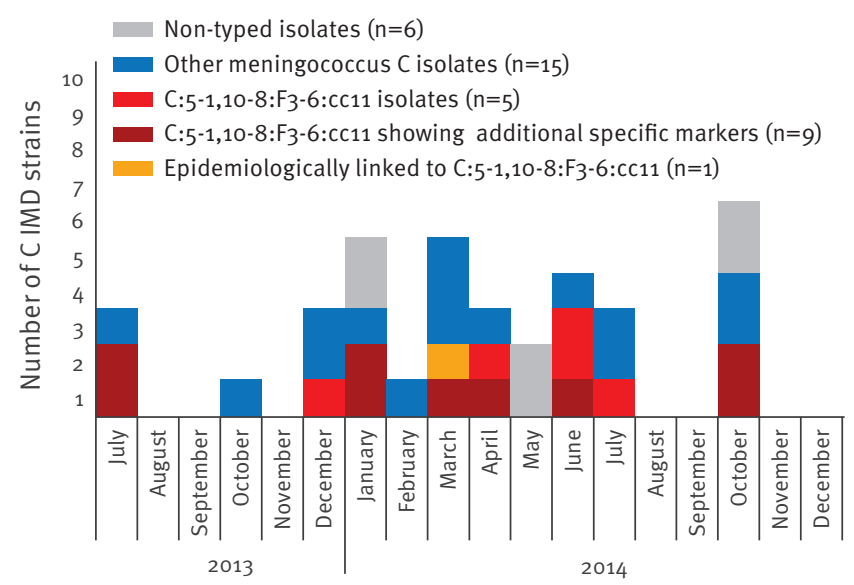

IMD: invasive meningococcal disease.
In order to estimate the incidence among MSM in the Paris region, we used as the denominator the estimated figures from the 2006 national survey on sexual behaviour [5]. About 175,000 men living in the Paris region and aged 25 to 59 years reported sexual encounters with men at least once during their life.

Taking into account the four cases notified in MSM since July 2013, the incidence of serogroup C IMD among 25 to 59 year-old MSM (individuals older than 25 years are not targeted by the national vaccination programme) in the Paris region was 2.28 per 100,000 person-years. The observed number of cases was 10 times greater than the expected number among men in this age group, if the incidence rate of C IMD cases was the same in Paris region than in all regions in France. No excess risk was demonstrated among men living in the Paris region who did not identify as MSM (Table 2 ).

\section{Public health response and discussion}

Surveillance of invasive meningococcal disease (IMD) in France relies on the mandatory reporting of cases to the French Institute for Public Health Surveillance (InVS) and the characterisation of invasive strains at the National Reference Centre (NRC) for Meningococci. Combined epidemiological surveillance and genetic typing of meningococcal isolates highlighted an increase of invasive meningococcal disease among MSM. These data suggested that the excess of serogroup C IMD cases among MSM living in the Paris region was linked to the circulation since mid-2013 of C:P1.5-1,10-8:F3-6:CC11 isolates with additional specific markers, not only in MSM but also among individuals (women, as well as those men who do not identify as MSM) who attend social venues associated with the gay community. Following the first outbreak reported in June 2013, the French Council of Public Health (HCSP) issued a recommendation for a three-month period of vaccination, with a meningococcal conjugate $C$ vaccine offered to all MSM aged 25 years and older, living in the Paris region and attending social venues associated with the gay community. This recommendation also included all individuals attending gay festivals

TABLE 1

Incidence and case fatality rates of serogroup C invasive meningococcal disease cases by age and sex, 1 July 2013-31 December 2014, Paris region $(n=36)$

\begin{tabular}{|c|c|c|c|c|c|c|c|}
\hline \multirow{2}{*}{ Age group } & \multicolumn{2}{|c|}{ Female } & \multicolumn{2}{|c|}{ Male } & \multicolumn{3}{|c|}{ Total } \\
\hline & Number & Incidence $^{a}$ & Number & Incidence $^{a}$ & Number & Incidence $^{a}$ & CFR \\
\hline <1 year & 1 & 1.17 & 0 & - & 1 & 0.57 & $0 \%$ \\
\hline 5-14 years & 1 & 0.13 & 1 & 0.13 & 2 & 0.13 & $0 \%$ \\
\hline $15-24$ years & 3 & 0.38 & 7 & 0.91 & 10 & 0.64 & $11 \%$ \\
\hline $25-59$ years & 6 & 0.20 & 11 & 0.39 & 17 & 0.29 & $12 \%$ \\
\hline$\geq 60$ years & 3 & 0.24 & 2 & 0.20 & 5 & 0.22 & $60 \%$ \\
\hline Total & 14 & 0.23 & 22 & 0.38 & 36 & 0.30 & $17 \%$ \\
\hline
\end{tabular}

CFR: case fatality rate.

a Incidence per 100,000 inhabitants. 
during summer 2013 in France [6]. Several health promotion activities were carried out during that summer by associations well-known in the gay community in France, but no vaccination campaign was officially performed. No data are available on the vaccine coverage reached in the targeted population.

Moreover, data from national surveillance highlighted that two family clusters of two cases each were also reported outside the Paris region in 2014, indicating that such isolates may spread all over the country and not only in the Paris region. Because of the high serogroup C IMD incidence due to the C:P1.5-1,10-8: $\mathrm{F}_{3}$ 6:cc11 isolates and the persistence of cases linked to the MSM community, the recommendation was renewed in November 2014 for one year and extended beyond the Paris region to the whole country, targeting MSM and all individuals aged 25 years and older attending social venues associated with the gay community [7]. Vaccination against serogroup C meningococci had been recommended in France since 2010 at the age of 12 months, with a catch-up in children and young adults ( 13 months to 24 years-old). However, the incidence of serogroup C IMD gradually increased between 2010 and 2013, mostly in infants younger than one year and in adults [8]. This increase suggested a lack of vaccine-induced herd immunity to reduce circulation of serogroup $\mathrm{C}$ meningococci, caused by low vaccine uptake ( $56 \%$ at the age of two years and $17 \%$ among the 15 to 19 year-olds in 2013).

\section{FIGURE 2}

Incidence rates $^{\mathrm{a}}$ of serogroup C invasive meningococcal disease cases France, 2010-14 (n=409)

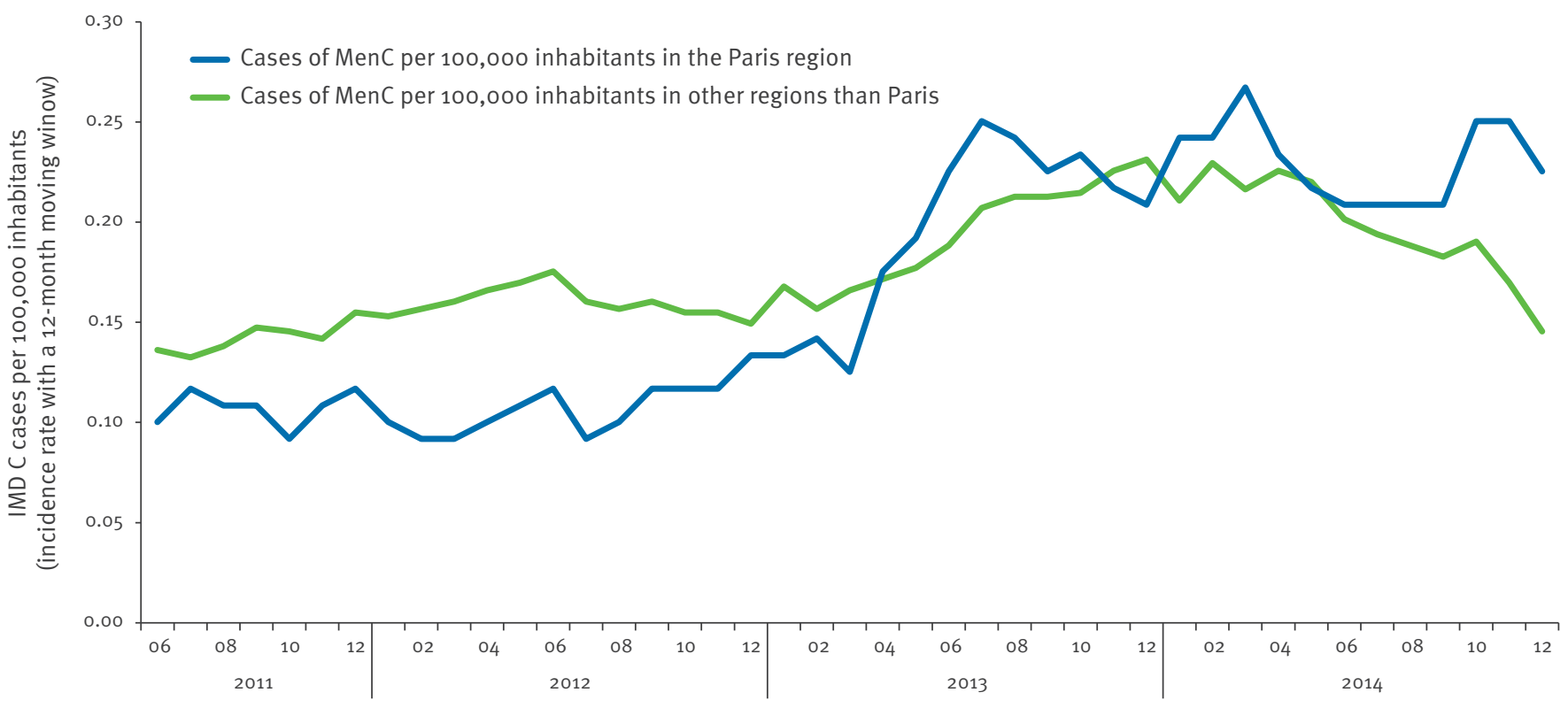

IMD: invasive meningococcal disease; MenC: meningococcus $C$.

a Moving averages calculated over the last 12 months moving window.

\section{TABLE 2}

Risk analysis of excess cases of serogroup C invasive meningococcal disease in 25-59 year-old MSM and men not identifying as MSM, Paris region, France, 1 July 2013-31 December $2014(\mathrm{n}=11)$

\begin{tabular}{|c|c|c|c|c|c|c|c|}
\hline \multirow{2}{*}{$\begin{array}{l}\text { Population of } 25-59 \text { year- } \\
\text { old men }\end{array}$} & \multirow{2}{*}{$\begin{array}{l}\text { Number of } \\
\text { C IMD cases }\end{array}$} & \multirow{2}{*}{$\begin{array}{l}\text { Incidence per } \\
100,000\end{array}$} & \multirow{2}{*}{$\begin{array}{l}\text { Expected } \\
\text { cases }\end{array}$} & \multicolumn{4}{|c|}{ Estimation of the risk excess of serogroup C IMD cases } \\
\hline & & & & $\mathrm{SIR}^{\mathrm{a}}$ & $\mathrm{p}$ value $\mathrm{b}^{\mathrm{b}}$ & Lower $\mathrm{Cl}$ & Upper Cl \\
\hline MSM & 4 & 2.28 & 0,39 & 10.16 & 0.001 & 2.73 & 26.02 \\
\hline Not MSM & 7 & 0.24 & 6,37 & 1.10 & 0.454 & 0.44 & 2.26 \\
\hline Total & 11 & 0.35 & 6,77 & 1.63 & 0.083 & 0.81 & 2.91 \\
\hline
\end{tabular}

$\mathrm{Cl}$ : confidence interval; IMD: invasive meningococcal disease; MSM: men who have sex with men; SIR: standardised incidence ratios.

a Indirect standardisation method: These ratios were calculated by dividing the observed number of cases in the Paris region by the expected number of cases derived from the incidence rates observed in France among men aged 25 to 59 years. The expected number was calculated by multiplying the number of the population of 25 to 59 year-old MSM living in Paris and exposed between July 2013 and December 2014 by the incidence rate of C IMD in all men of that age living in France and exposed in that period (person-years).

b $p$ values were calculated by unilateral exact test based on a Poisson distribution; $p<0.025$ was defined as a significant excess of cases.

The Table shows that MSM living in the Paris region and aged for 25-59 years have a 10 times higher risk to contract a serogroup C IMD than the same population living in other regions in France. 
Vaccine policy for targeting 1 to 24 year-olds should be strengthened more efficiently in France. In addition, enhanced microbiological and epidemiological surveillance should be currently maintained for the isolates responsible of continuous spread of invasive MenC among MSM and adults older than 25 years attending social venues associated with the gay community.

\section{Acknowledgements}

We gratefully acknowledge the local public health officers, in particular J. Schachmann from the Health Agency in the Paris region for collecting the relevant information, and $D$. Antona, A. Velter and S. Levu from the French Institute for Public Health Surveillance for their thoughtful comments. We also wish to thank to local laboratories for sending samples to the National Reference Centre for Meningococci to conduct further molecular typing of strains.

\section{Conflict of interest}

None declared.

\section{Authors' contributions}

L. Aubert drafted the manuscript, analysed data from epidemiological and molecular surveillance and conducted to risk analysis in Paris region. $\mathrm{M}-\mathrm{K}$ Taha supervised molecular typing of the bacterial isolates from IMD cases on the territory, initiated retrospective molecular typing of strains with a similar combination of genotypic characteristics as the initial cluster of C IMD cases detected in June 2013, initiated enhanced surveillance of these isolates in France and largely contributed to the manuscript. N. Boo coordinated the outbreak investigation in Paris region, collected cases' information about a possible link with the MSM community and contributed to the manuscript. Y. Le Strat contributed to risk analysis and to the manuscript. A-E Deghmane contributed to molecular typing of the bacterial isolates received at the National Reference Centre for Meningococci and contributed to the manuscript. A. Sanna contributed to the risk analysis and to the manuscript. AS Barret participated in the initial three-case cluster investigation in June 2013 and contributed to the manuscript. D. Levy Bruhl was involved in the establishment by the French Council of Public Health (HCSP) of the recommendation targeting MSM in 2013 and the renewal of this recommendation in November 2014 and contributed to the manuscript. S Vandentorren contributed to the analysis of epidemiological situation in Paris region and to the manuscript. I. Parent du Châtelet coordinated outbreak investigation in the initial three-case cluster, coordinated epidemiological surveillance and outbreak investigation of IMD cases in France, participated at the recommendations established in 2013 and 2014 by the HCSP, supervised this analysis and contributed actively to the manuscript.

\section{References}

1. Marcus U, Vogel U, Schubert A, Claus H, Baetzing-Feigenbaum J, Hellenbrand W, et al. A cluster of invasive meningococcal disease in young men who have sex with men in Berlin, October 2012 to May 2013. Euro Surveill. 2013;18(28):20523. Available from: http://dx.doi.org/10.2807/1560-7917. ES2013.18.28.20523 PMID:23870095

2. Weiss D, Varma JK. Control of recent community-based outbreaks of invasive meningococcal disease in men who have sex with men in Europe and the United States. Euro Surveill. 2013;18(28):20522. Available from: http://dx.doi. org/10.2807/1560-7917.ES2013.18.28.20522 PMID:23870094
3. European Centre for Disease Prevention and Control (ECDC). Invasive meningococcal disease among men who have sex with men. Rapid risk assessment. Stockholm: ECDC; 2013. Available from: http://www.ecdc.europa.eu/en/publications/ Publications/rapid-risk-assessment-invasive-meningococcaldisease-among-MSM.pdf

4. Simon MS, Weiss D, Gulick RM. Invasive meningococcal disease in men who have sex with men. Ann Intern Med. 2013;159(4):300-1. Available from: http://dx.doi. org/10.7326/0003-4819-159-4-201308200-00674 PMID:23778867

5. Bajos N, Bozon M. Enquête sur la sexualité en France. Pratiques, genre et santé. [Survey on sexuality in France]. Paris: Editions La Découverte; 2008. ISBN : 9782707154293. French.

6. Haut Conseil de la santé publique (HCSP). Avis relatif aux recommandations de vaccination contre le méningocoque $\mathrm{C}$ au-delà de 24 ans, notamment chez les hommes ayant des relations sexuelles avec d'autres hommes (HSH). [Notice regarding vaccination recommendations against meningococcal C beyond 24 years, particularly among men who have sex with men (MSM)]. Paris: HCSP; 2013. French. Available from http://www.hcsp.fr/Explore.cgi/Telecharger?N omFichier=hcspa20130701_infectionmeningocvaccplus24ans. pdf

7. Haut Conseil de la santé publique (HCSP). Avis relatif aux recommandations de vaccination contre les infections invasives à méningocoque $\mathrm{C}$ au-de là de 24 ans, notamment chez les hommes ayant des relations sexuelles avec d'autres hommes (HSH) [Notice regarding vaccination recommendations against meningococcal $C$ beyond 24 years, particularly among men who have sex with men (MSM)]. Paris: HCSP; 2014. French. Available from http://www.hcsp.fr/Explore.cgi/Telecha rger?NomFichier=hcspa20141107_vaccmeningChplus24anshsh. pdf

8. Barret AS, Deghmane AE, Lepoutre A, Fonteneau L, Maine C, Taha MK, et al. Les infections invasives à méningocoques en France en 2012: principales caractéristiques épidémiologiques. [Invasive meningococcal disease in France in 2012: main epidemiological features]. Bull Epidémiol Hebd. 2014;(12):25-31. French. Available from: http://www.invs.sante.fr/ beh/2014/1-2/2014_1-2_4.html 